\title{
Reseñas Sitios en Internet
}

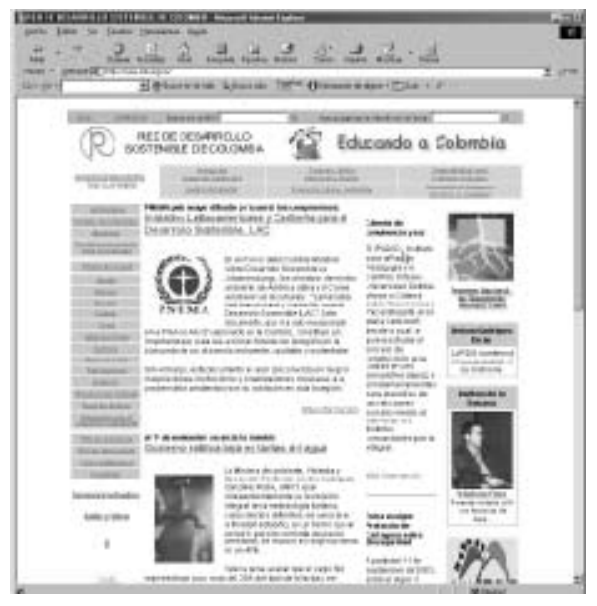

\section{Red de Desarrollo Sostenible de Colombia: http://www.rds.org.co}

\section{¿Hasta dónde se extienden los lazos del desarrollo?, ¿hasta dónde se extenderían si el desarrollo tiene como característica principal la sostenibilidad?.}

Esos son algunos de los aspectos tratados por la página web colombiana Red de Desarrollo Sostenible de Colombia (RDSC); allí, se realiza una lectura minuciosa de las diversas vertientes del desarrollo tanto en la escala humana, económica, cultural y política, como en los ámbitos local, nacional e internacional.

Es una página para aquellos que tienen ansiedad por abordar y comprender la complejidad que subyace bajo uno de los aspectos que más inquietan a las sociedades de nuestro tiempo: el desarrollo sostenible. De igual manera, esta web, permite tener la visión de múltiples miradas sobre el mismo.

Y por ello, da la oportunidad de expandir las posibilidades de comprensión y acción del usuario además de motivarlo a tomar posición y participar de los procesos. El desarrollo se reinventa a través de la participación de los sujetos so jales. La RDSC, está al tanto de dichos cambios, para masificarlos y transformarlos. 


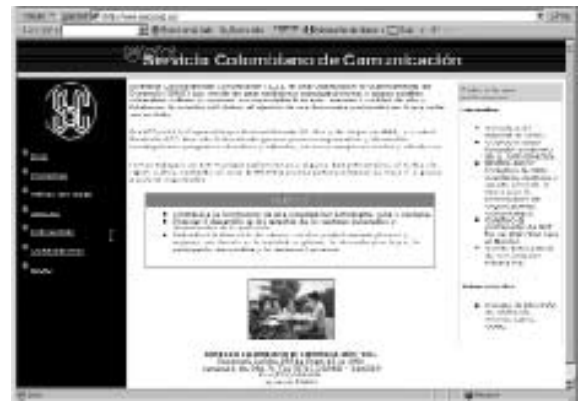

\section{Servicio Colombiano de Comunicación: http://www.sercol.org.co}

El capital humano, como valuarte fundamental dentro de las dinámicas de las sociedades, es un bien inexplorado y con potencialidades prácticamente ilimitadas.

¿Cómo aprovecharlo y cultivarlo?, mediante la gestión desde cada una de sus partes: los individuos que componen a la sociedad.

El Servicio Colombiano de Comunicación (SCC), es una web que impulsa el trabajo desde las comunidades para mejorar ese capital base de toda nación.

Algunas de las áreas de trabajo de esta organización, son:

* Género y Formación pedagógica y ciudadana.

* Capacitación y acompañamiento de grupos de mujeres, particularmente Madres Comunitarias.

* Formación de Educadoras Populares.

* Escuela de Formación Permanente para mujeres: Madres

* Economía Solidaria.

* Comunicación para la convivencia.

* Ecología.

Desde ese punto de vista, la SCC trabaja desde la base de la sociedad, pues comprende que es allí el punto de partida de toda reflexión y acción colectivc"zlestinada al mejoramiento de la calidad de vida de los sujetos sociales. 


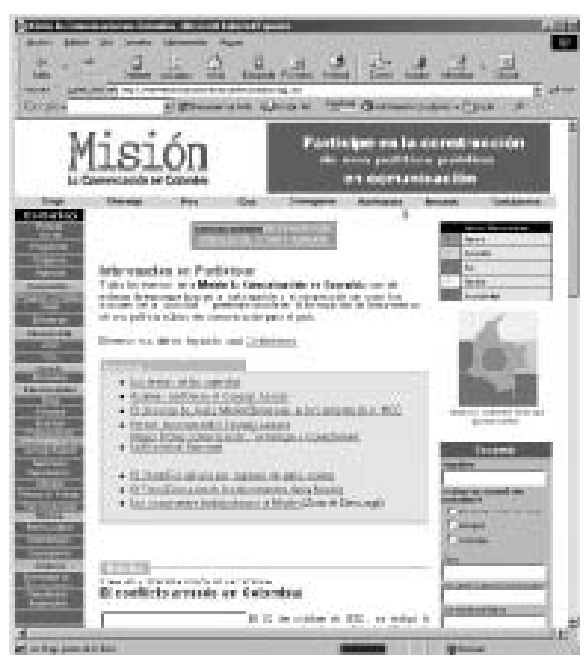

Misión la Comunicación en Colombia:

http://www.misionlacomunicacionencolombia.org.co

La comunicación como ciencia y como cotidianidad, es una red que se extiende transversalmente por todo el inmenso universo que se constituye como sociedad.

En ese sentido, la web de Misión la Comunicación en Colombia, es precisamente esa urdimbre que teje a través de las distancias, las puntadas necesarias para conjugar los hilos de la comunicación en su sentido cotidiano y científico, pues entiende que solamente mediante la confluencia de esas dos vías, se podrá gestionar una política pública sustentable en comunicación, para y con el empoderamiento de la sociedad civil, capaz de incidir en dichos temas.

La misión, trabaja por nodos, cinco en total, que se establecen en amplias zonas del país; centro, oriente, sur, caribe y occidental, con el animo de realizar una mirada diferente a la comunicación, y su relación con los ámbitos políticos, sociales y económicos, que han signado el rumbo de la nación.

La web, es entonces el espacio virtual donde el visitante puede hacer y ser parte del esfuerzo conjunto por hacer que la comunicación como ciencia, sea ura práctica cotidiana de la sociedad colombiana para 